\section{Photosynthesis and Root Respiration in Ilex crenata 'Rotundifolia' at Supraoptimal Root-zone Temperatures}

\author{
William J. Foster ${ }^{1}$, Dewayne L. Ingram, and Terril A. Nell \\ Ornamental Horticulture Department, Institute of Food and Agricultural \\ Sciences, University of Florida, Gainesville, FL 32611
}

Additional index words. heat stress, Japanese holly, container production

\begin{abstract}
Rooted stem cuttings of Ilex crenata Thunb. 'Rotundifolia' were grown in a controlled-environment growth chamber. Root-zone temperatures were controlled with an electric system. Shoot carbon exchange and root respiration rates were determined in response to root-zone temperatures of $28,32,36$, and $40 \mathrm{C}$ for $6 \mathrm{hour}^{-\mathrm{day}^{-1} \text { for } 7}$ days. Photosynthesis was decreased by root zones $\geq 32 \mathrm{C}$, while root respiration increased with increasing root-zone temperature. Decreased photosynthetic rates were not due to increased stomatal resistance.
\end{abstract}

Reduced shoot and root growth has been reported for many species in response to high root temperatures (Gur et al., 1972; Johnson and Ingram, 1984). Decreased photosynthetic rates and increased root respiration contribute to such growth reduction. Johnson and Ingram (1984) reported reduced photosynthetic rates in pittosporum (Pittosporum tobira Thunb.) after 6 months at supraoptimal root-zone temperatures. Szaniawski and Kielkiewicz (1982) found that maintenance respiration was greater at supraoptimal root temperatures and this was related to increased root respiration.

The temperature at which increased respiration and decreased photosynthesis result in no net gain in carbon is termed the temperature compensation point (TCP) (Levitt, 1980). As the temperature increases above the TCP, carbohydrate reserves are depleted. Starvation induced by high temperatures could contribute to reduced plant growth and yield depression (Chen et al., 1982). The existence of a TCP in response to supraoptimal root-zone temperatures has never been reported. Therefore, this study was conducted to determine root respiration and shoot carbon exchange rates for Ilex crenata 'Rotundifolia' exposed to supraoptimal root-zone temperatures for 1 week.

Plant material. Stem cuttings of 'Rotundifolia' holly were taken on 19 Mar. 1985 and rooted directly in white cone-shaped containers $(21 \times 4 \mathrm{~cm}$ tapering to $1 \mathrm{~cm})$ that had 20,0.5-cm-diameter holes equidistant around the length of each cone-shaped container to increase air exchange when measuring root respiration. The cone-shaped containers contained milled pine bark amended with $1.77 \mathrm{~kg}$ of a micronutrient

Received for publication 12 July 1989. Florida Experiment Station Journal Series no. 8004. The cost of publishing this paper was defrayed in part by the payment of page charges. Under postal regulations, this paper therefore must be hereby marked advertisement solely to indicate this fact.

'Present address: Horticultural Services Manager, Grace-Sierra Horticultural Products Co., 1310 Carson Road East, Mobile, AL 36695-3518. formulation $/ \mathrm{m}^{3}$ (Perk; Vigiro Industries, Fairview Heights, 111.) and $2.97 \mathrm{~kg}$ dolomitic limestone $/ \mathrm{m}^{3}$. Plants were placed under intermittent mist until well-rooted and subsequently transferred to a greenhouse, where they were watered daily and fertilized weekly with a soluble $20 \mathrm{~N}-8.6 \mathrm{P}-16 \mathrm{~K}$ fertilizer (Peters 20-20-20; Grace-Sierra Horticultural Products Co., Milpitas, Calif.) with Nat 300 $\mathrm{mg} \cdot \mathrm{liter}^{-1}$. Plants were transferred to a growth room 2 weeks before treatment.

Growth room. Beginning 14 Mar. 1986, root-zone temperature treatments of 28,32 , 36 , and $40 \mathrm{C}$ were initiated in a $3.1 \times 7.6-$ $\mathrm{m}$ walk-in growth room. The root zone was at $28 \mathrm{C}$, as measured on the inside wall of rates at selected root-zone temperatures. the cone-shaped containers before treatment (Thermocouple thermometer; Wescor, Logan, Utah). Root zones were maintained $\pm 0.3 \mathrm{C}$ within each tube for the desired rootzone temperature using an electronically controlled root-heating system (Ingram et al., 1986). Irradiance was supplied by phosphorcoated Metal-arc lamps (GTE Sylvania Corp., Manchester, N.H.) and provided a photosynthetic photon flux (PPF) of 1100 $\mu \mathrm{mol} \cdot \mathrm{s}^{-1} \cdot \mathrm{m}^{-2}$, as measured at plant height with a LI-COR Model LI-185A quantum/radiometer/photometer (LI-COR, Lincoln, Neb.). The light source, controlled by a time clock, provided a photoperiod of $14 \mathrm{~h}$, resulting in an abrupt change between light/ dark phases and a 30C (day)/24C (night) thermoperiod.

Plants were placed in the growth room in a completely randomized design with four single-plant replicates per root-zone temperature treatment. Treatment temperatures were maintained for $6 \mathrm{~h} \cdot \mathrm{day}^{-1}$ from 1000 to 1600 HR for 7 days. Pre- and post-treatment shoot and root carbon exchange rates were measured in an assimilation chamber.

Assimilation chamber. Shoot and root carbon exchange rates (CER) were measured in a plexiglass assimilation chamber. Plexiglass, $0.64 \mathrm{~cm}$ thick, was used to construct the chamber measuring $30.5 \times 30.5 \times 61.0$ $\mathrm{cm}$ (length $\times$ width $\times$ height). The chamber (Fig. 1) was divided in half by a 30.5 $\times 30.5-\mathrm{cm}$ removable section of plexiglass with a 4-cm-diameter hole in the center. The plexiglass sheet was sealed with modeling clay and tightly secured. Shoot chamber volume measured 27.1 liters and the root sec-

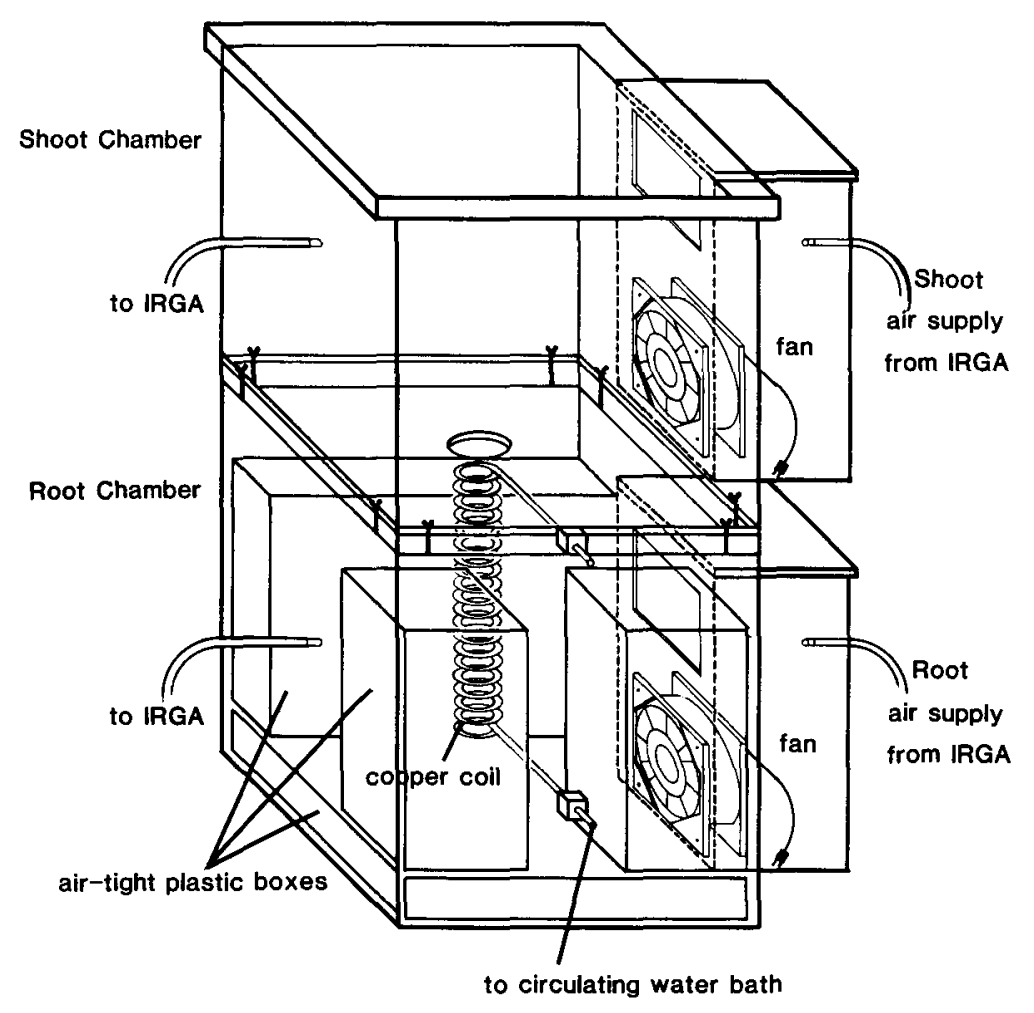

Fig. 1. Diagram of assimilation chamber used to measure whole-plant shoot and root carbon exchange 


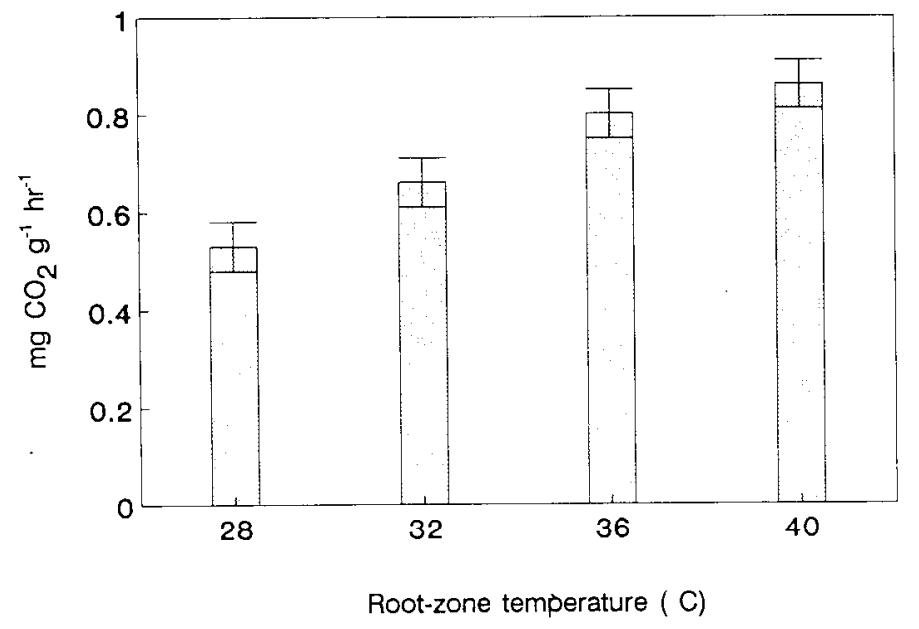

Fig. 2. Adjusted post-treatment mean root respiration rates for Ilex crenata 'Rotundifolia' grown at four root-zone temperatures for $6 \mathrm{~h}$ each day for 7 days. Bars represent \pm 1 sE based on four singleplant replicates per treatment temperature.

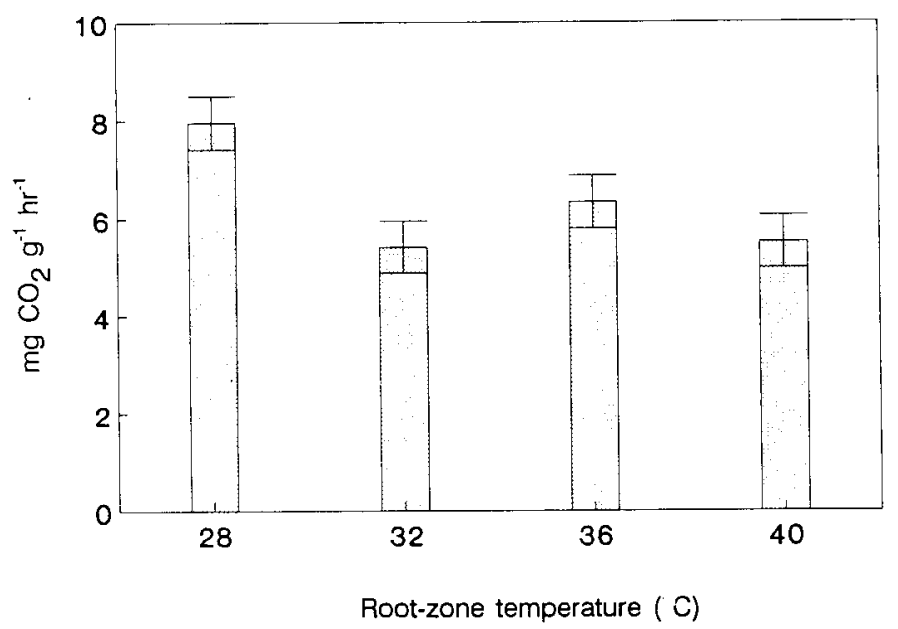

Fig. 3. Adjusted post-treatment mean shoot carbon exchange rates for Ilex crenata 'Rotundifolia' grown at four root-zone temperatures for $6 \mathrm{~h}$ each day for 7 days. Bars represent $\pm 1 \mathrm{SE}$ based on four single-plant replicates per treatment temperature.

tion was reduced to 13.6 liters with air-tight plexiglass cubes. "Muffin" fans (Digi-Key Corp., Thief River Falls, Minn.), $8 \times 8 \mathrm{~cm}$, circulated air in the chamber at a rate of 0.02 $\mathrm{m}^{3} \cdot \mathrm{s}^{-1}$.

Copper tubing, $0.8 \mathrm{~cm}$ in diameter, surrounded the cone-shaped container (not shown in diagram) when inserted into the assimilation chamber. Water, heated to a treatment temperature, was circulated through the copper coil using a temperature-regulating water pump (Lauda K-2/R; Brinkman Instruments, Westbury, N. Y.) that provided uniform heat distribution and allowed rapid temperature adjustment. Root-zone temperatures were monitored with two thermocouples placed on the inside wall of the cone-shaped container 5 and $20 \mathrm{~cm}$ from the top and were maintained within $\pm 0.3 \mathrm{C}$.

CER measurements. CER measurements were obtained using an infrared gas analyzer (Anarad model AR-600R; Anarad, Santa Barbara, Calif.). A plant was placed in the assimilation chamber with the root system in the lower half of the chamber and the shoot rates due to transpiration and evaporation (von Caemmerer and Farquhar, 1981). Shoot CER was calculated using leaf area and dry weight, while root respiration was based on dry weight. Pretreatment root and shoot CERS (root zone at 28C) were used as covariates in an analysis of covariance, and adjusted post-treatment root and shoot CER means were determined.

Average shoot CER was $7.52 \pm 0.62$ (SE) $\mathrm{mg} \mathrm{CO} / \mathrm{dm}^{2}$ per hour before treatment. Posttreatment adjusted-mean CERS expressed on a dry-weight basis exhibited a high degree of variability due to differences in plantto-plant photosynthetic rate. Pre- and posttreatment mean CERS were in the range of previously reported rates for woody plant species (Lawrence and Oechel, 1983). The mean pretreatment root respiration rate (root zone at 28C) was $0.53 \pm 0.04(\mathrm{SE}) \mathrm{mg} \mathrm{CO} /$ $\mathrm{g}$ dry weight per hour and was in the range of previously published rates for whole-root systems of Scots pine (Pinus sylvestris L.) (Szaniowski, 1981).

Adjusted post-treatment root respiration rates increased with increasing root temperature from 28 to 36C (Fig. 2). Szaniawski and Kielkiewicz (1982) reported root maintenance respiration increased with increasing room temperature in sunflower (Helianthus annuus L. 'Autumn Beauty'), while root growth respiration was not affected by root temperature. Increased maintenance respiration is the probable explanation for the increased root respiration rates with increasing root-zone temperatures found in this study.

Our results are in agreement with those of Gent and Enoch (1983), who proposed that increased maintenance respiration at supraoptimal growing temperatures resulted in insufficient carbohydrate levels needed for growth respiration, resulting in decreased growth, Decreased growth of pittosporum due to supraoptimal root-zone temperatures, as reported by Johnson and Ingram (1984), may be explained, in part, by increased maintenance respiration.

Adjusted post-treatment shoot CER was reduced $32 \%$ after a 7 -day exposure to $32 \mathrm{C}$ compared to the $28 \mathrm{C}$ control (Fig. 3). There were no further decreases in shoot CER for root zones at 36 or $40 \mathrm{C}$. Decreased photosynthetic rates in response to prolonged exposure to supraoptimal root temperature have been reported previously (Johnson and Ingram, 1984). Such decreases in shoot CERS could be due to decreased chlorophyll content in response to decreased cytokinin activity at elevated root-zone temperatures (Gur et al., 1972).

Post-treatment transpiration rates were similar for all treatments; they averaged between 4 and $6 \mathrm{mg} \mathrm{H}_{2} \mathrm{O} / \mathrm{m}^{2}$ per second. Therefore, increased stomatal resistance can be disregarded as a possible reason for reduced shoot CERS with root zones > 28C. This study supports the hypothesis that nonstomatal inhibition of photosynthesis can occur in response to supraoptimal root-zone temperatures.

Determination of a TCP was not possible because dark respiration rates were not de- 
termined. However, an estimated partial carbon balance was calculated using CERS and plant dry weights. For example, plants grown with the root zone at 40C had a CER of $194.7 \mathrm{mg} \mathrm{CO} /$ plant per day under a 14 -h photoperiod (from: $5.52 \mathrm{mg} \mathrm{CO} / \mathrm{hr} \times 2.52$ g dry weight/shoot $\times 14 \mathrm{~h}$ ), but through root respiration, $97.7 \mathrm{mg} \mathrm{CO} /$ plant per day (from: $0.86 \mathrm{mg} \mathrm{CO} / \mathrm{g}$ dry weight per hour $\times 6.65$ g dry weight/root $\times 6 \mathrm{~h}+0.53 \mathrm{mg} \mathrm{CO}_{2} / \mathrm{g}$ dry weight per hour $\times 6.65 \mathrm{~g}$ dry weight/ root $\mathbf{x} 18 \mathrm{~h}$ ) were lost. The estimated partial carbon balance would be $97.0 \mathrm{mg} \mathrm{CO} /$ plant per day. The TCP is at a net carbon balance of $0.0 \mathrm{mg} \mathrm{CO}_{2}$, but the estimated partial carbon balance associated with root-zone temperatures did not approach $0.0 \mathrm{mg} \mathrm{CO}_{2}$ under the conditions tested. The shoot net gain in fixed $\mathrm{CO}_{2}$ does not include nyctoperiod loss of $\mathrm{CO}_{2}$ through dark respiration. Using dark respiration rates reported by Limbach et al. (1982), we assumed that this would not substantially contribute to the estimated partial carbon balance for 'Rotundifolia' holly.

Decreased growth associated with supraoptimal root-zone temperatures from 32 to $40 \mathrm{C}$ would result from decreased $\mathrm{CO}_{2}$ fixation and increased loss of $\mathrm{CO}_{2}$ through root respiration. The mean photosynthetic rate was $32 \%$ lower when root zones were at $32 \mathrm{C}$ than at $28 \mathrm{C}$. Between these two root-zone temperatures, there appears to be the synthesis or destruction of compound(s) or the occurrence of physiological processes that substantially reduce photosynthesis. The mechanisms involved in decreased photosynthesis due to a 7-day exposure to rootzone temperatures between 32 and $40 \mathrm{C}$ were not determined. Exposure of root zones to 32 to $40 \mathrm{C}$ for longer than 1 week could result in a further decrease in net carbon fixation.

\section{Literature Cited}

Chen, H.-H., Z.-Y. Shen, and P.H. Li. 1982. Adaptability of crop plants to high temperature stress. Crop Sci. 22:719-725.

Gent, M.P. and H.Z. Enoch. 1983. Temperature dependence of vegetative growth and dark respiration: A mathematical model. Plant Physiol. 71:562-567.

Gur, A., B. Bravdo, and Y. Mizrahi. 1972. Physiological responses of apple trees to supraoptimal root temperature. Physiol. Plant. 27:130138.

Ingram, D. L., B. Basford, W.J. Foster, and C. Ramcharon. 1986. Electronically controlled heating tubes for root heat stress research. HortScience 21:934. (Abstr.)

Johnson, C.R. and D.L. Ingram. 1984. Pittosporum tobira response to container medium temperature. HortScience 19:524-525.

Lawrence, W.T. and W.C. Oechel. 1983. Effects of soil temperature on the carbon exchange of taiga seedlings. H. Photosynthesis, respiration, and conductance. Can. J. For. Res. 13:850859.

Levitt, J. 1980. Responses of plants to environmental stresses. vol. 1. Chilling, freezing, and high temperature stresses. Academic, New York.

Limbach, W. E., W.C. Oechel, and W. Lowell. 1982. Photosynthetic and respiratory responses to temperature and light of three Alaskan tundra growth forms. Holartica Ecol. 5:150-157.

Sestak, Z., P.G. Jarvis, and J. Catsky. 1971. Cri- teria for the selection of suitable methods, $\mathrm{p}$. 1-48. In: Z. Sestak, P.G. Jarvis, and J. Catsky (eds.). Plant photosynthetic production: Manual of methods. W. Junk N.V. Publishers, The Hague, Netherlands.

Szaniawski, R.K. 1981. Growth and maintenance respiration of shoot and roots in Scots pine seedlings. Z. Pflanzenphysiol. 101:391-398.
Szaniawski, R.K. and M. Kielkiewicz. 1982. Maintenance and growth respiration in shoots and roots of sunflower plants grown at different root temperatures. Physiol. Plant. 54:500-504. von Craemmerer, S. and G.D. Farquhar. 1981. Some relationships between the biochemistry of photosynthesis and the gas exchange of leaves. Planta 153:376-387. 